\title{
An Anthropometric Study of some Basic Nasal Parameters of Three Major Ethnic Groups in Kogi State, Nigeria
}

\author{
Oluwayinka Paul ${ }^{1,2}$, Olatunji Sunday Yinka ${ }^{1}$, Adelodun Stephen Taiye ${ }^{1}$, Amlabu Mana Gift ${ }^{2, *}$ \\ ${ }^{1}$ Department of Anatomy and Cell Biology, Obafemi Awolowo University, Ile-Ife, Nigeria \\ ${ }^{2}$ Department of Anatomy, College of Health Sciences, Bingham University, Nasarawa, Nigeria
}

\section{Email address:}

oluwadele@yahoo.com (O. Paul), adajosunday@yahoo.com (O. S. Yinka), adeloduntaiye@gmail.com (A. S. Taiye), giftamlabu94@gmail.com (A. M. Gift)

\section{To cite this article:}

Oluwayinka Paul, Olatunji Sunday Yinka, Adelodun Stephen Taiye, Amlabu Mana Gift. An Anthropometric Study of some Basic Nasal Parameters of Three Major Ethnic Groups in Kogi State, Nigeria. American Journal of Clinical and Experimental Medicine.

Vol. 3, No. 2, 2015, pp. 62-67. doi: 10.11648/j.ajcem.20150302.13

\begin{abstract}
Nasal anthropometry can be employed in identification of the race and sex of individuals whose identity is unknown, since normal nose morphology is dependent on gender, ethnic and environmental influences. Nasal index is an ethnic sensitive anthropometrical tool and also exhibits sexual differences. This study is aimed at providing anthropometric data on the basic nasal parameters (nasal height, nasal width and nasal index) of three major ethnic groups (Okun, Igala and Ebira) in Kogi State, Nigeria. The study sample comprised 302 subjects aged 17-45 years; 109 Okun subjects comprising of 57 males and 52 females, 107 Igala subjects comprising of 55 males and 52 females and 86 Ebira subjects comprising of 55 males and 31 females. The nasal height and nasal width were measured using a sliding vernier calliper and the nasal index was calculated. Test for significance was done using independent t-test and ANOVA. The result from this study showed that the mean nasal index for Okun males and females were 97.23 \pm 7.89 and 93.64 \pm 8.22 respectively; the mean nasal index for Igala males and females were $97.21 \pm 8.88$ and $93.48 \pm 8.72$ and the mean nasal index for Ebira males and females were $96.93 \pm 8.66$ and $92.99 \pm 7.62$ respectively. Sexual dimorphism was noted in the nasal parameters of males and females in each ethnic group at $\mathrm{P}<0.05$ but there was no significant difference in the nasal parameters between the ethnic groups considered at $\mathrm{p}<0.05$. Okun, Igala and Ebira fall under the platyrrhine nose type. The result of this study will be relevant in forensic medicine, physical anthropology and clinical practice.
\end{abstract}

Keywords: Nasal, Okun, Igala, Ebira, Anthropometry

\section{Introduction}

Variation is one of the most important phenomena occurring in humans, and it has been attributed to a number of factors such as mutation and natural selection. Many studies have emphasized the importance of anthropometric measurements as a means of studying variation in human populations as well as an important tool in forensic science for crime detection [1]. In the 20th century, the application of anthropometry to the study of racial types was replaced by more sophisticated techniques for evaluating racial differences. Recently, anthropometry has found increase use in medical sciences especially in the discipline of forensic medicine [1]. Nasal anthropometry is the study concerned with the measurements of the proportion, size and shape of the human nose [2]. The knowledge of nasal anthropometry is useful in forensic medicine and physical anthropology, as one of the tools used in identification of different races, ethnicity and gender of an individual [3].

There are several studies concerning nasal indices among ethnic groups in Nigeria with some comparisons between them. However, data are still lacking on whether individuals from different ethnic groups that share same environment have the same nose type, since climate is believed to influence the variety of noses [4].

The nasal index is expressed as the percentage of the width in relation to the height of the nose. On the skeleton, the height is measured from the nasion (where the internasal suture touches the frontal bone) to a point just at the base of the nasal spine. The width is the maximum distance on the nasal opening in the skull. In case of living subject, the height is to be taken from nasion to the subnasale (where the nasal septum touches the upper lip). The nasal width is the 
highest distance between the two alae or two nasal wings in natural condition. Normally, the nasal index on skeleton and the nasal index on the living subject never correspond to one another [5].

In anthropology and forensic medicine, the knowledge of nasal index is relevant in distinguishing the race, ethnicity and sex of individuals whose identity is not known $[1,6]$. Nasal index is also useful in the analysis and classification of fossil remains as well as the study of living population [7].

In clinical practice, nasal index is useful in rhinoplastic surgery (plastic surgery of the nose) as nasal analysis is the first step a rhinoplastic surgeon takes to change the size or shape of the nose for a desired aesthetic effect. Also, nasal analysis of a particular ethnic group can help the rhinoplastic surgeon change the shape of nose of a patient without compromising the patient's desire to maintain his cosmetic status [8].

Nasal index measurement in healthy individuals is also useful for dysmorphologists in the early diagnosis of some dysmorphic syndromes like cleft lip and cleft palate which are associated with nose disorders [3].

\subsection{Nasal Index as an Anthropometric Tool}

Nasal index is the ratio of nasal width (NW) to nasal height $(\mathrm{NH})$ multiplied by 100 [9]. Nasal Width (NW) is measured as a straight distance at right angle to the nasal height from ala to ala. The Nasal Height (NH) is measured as a distance between the nasion and subnasale [1].

Various studies have indicated racial and ethnic differences in nasal index amongst different populations. The shape of the nose can be determined by environmental climate conditions [10] with narrower nose being favoured in cold and dry climate and broader nose in warmer and moist climates as a result of natural selection [9].

The people with broad nose and wide nasal aperture generally live under hot moist conditions where they can inhale large quantities of warm and moist air without causing any harm to their respiratory organs. On the contrary, the people in cold and dry climate possess the narrower and longer nose which is more effective in warming the cold air before it passes on to the lungs [5].

\subsection{Nose Types Based on Nasal Index Classification}

There is a wide variation in the size and shape of the nose and ethnic influences can result in different appearance of the nose [11]. The shape of human nose can be classified based on morphology and nasal indices $[12,13]$.

Morphologically, the human nose can be classified into;

- roman or aquiline nose,

- the Greek or straight nose,

- the Nubian nose,

- the hawk nose,

- the snub nose and

- the celestial or turn up nose

The Roman or Aquiline Nose is convex in shape, like a hook. It is also known as 'hooknose' because of its shape. The
Greek or Straight Nose is perfectly straight with no curves or hooked like shape. The Nubian Nose has wide nostrils, it is generally a little narrow at the top, thick and broad at the middle and wide at the end. The Hawk Nose is so called because it is very convex, to the extent that it almost looks like a bow. It is very thin and sharp as well. Snub Nose is quite short in length and is neither sharp, nor hook like nor wide. The turn up Nose is also called as the Celestial nose; it is so called because it runs continuously from the eyes towards the tip [12].

Based on nasal index, the nose can be classified into;

- leptorrhine (long and narrow nose),

- the mesorrhine (medium) and

- the platyrrhine (broad nose) nose types.

A nose type is said to be leptorrhine if the nasal index is 69.9 or less, mesorrhine if the nasal index is between $70-84.9$ and platyrrhine if the nasal index is 85 and above [6,14]. The platyrrhine nose type is characterized by a very prominent ala lobule with a full or rounded nasal tip. The mesorrhine nose type is characterized by a less prominent lobule with a more defined nasal tip and the leptorrhine type of nose is characterized by least prominent ala lobule with a well defined nasal tip [15].

Most Caucasians have the leptorrhine type of nose which is long and narrow. The Indo-Aryan is also similar to the European, possessing a fine nose [16]. In Jingpo people in China are mesorrhine [17]. Indo-African [16] and AfroAmerican [18] have platyrrhine nose type. Risley [19] reported that the nasal index of Africans is basically platyrrhine. Carleton [20] showed that the negroid race mainly of African descent have the platyrrhine type of nose. Sarka [5] reported that the nose of Australian aborigines differ from that of the Negros by more deeply depressed root.

\subsection{Kogi State}

Kogi State is one of the states in North-Central zone of Nigeria. The state capital, Lokoja is located between latitudes $7^{0} 46^{1} \mathrm{~N}-7^{0} 52^{1} \mathrm{~N}$ and longitudes $6^{0} 38^{1} \mathrm{E}-6^{0} 46^{1} \mathrm{E}$ [21]. The rainfall in this part of the country is between 804.5$1767.1 \mathrm{~mm}$ with dry and wet seasons and mean annual temperature of $28.03^{\circ} \mathrm{C}$ [21]. Igala, Ebira and Okun are the major ethnic groups in Kogi State. The Igala are the main ethnic group east of Niger while the Ebira and Okun live west of the river [22].

\section{Materials and Methods}

\subsection{Sample Population}

The study was carried out using a total sample size of three hundred and two (302) subjects which comprised of one hundred and nine (109) Okun subjects of which fifty-seven (57) were males and fifty-two (52) were females, one hundred and seven (107) Igala subjects of which fifty-five (55) were males and fifty-two (52) were females and eightysix (86) Ebira subjects of which fifty-five (55) were males and thirty-one (31) were females. Subjects were selected by 
random sampling from Kogi State University, Anyigba, Kogi State. The ages studied were between 17-45 years.

\subsection{List of Tools Used in Data Collection}

A manual type of sliding vernier calliper by Esal, China; SPSS 14.0, Microsoft Excel 2007, a questionnaire which consisted of sex, age, tribe and tribe of parents of the subject, pen, and notebook.

\subsection{Criteria for Inclusion or Exclusion}

The subjects were Okun, Igala or Ebira by both parents.

Subjects who had trauma of the nose, cleft lip or cleft palate were excluded from the study also subjects who had a history of plastic surgery of the nose were excluded.

\subsection{Measurements}

The direct method described by Anas and Saleh, 2014 was used. With this method, measurements were done with subjects sitting on the chair in a relaxed condition and head in anatomical position (directed anteriorly). Measurements were done by one observer to prevent inter-observer error and each measurement was taken twice and average taken. The measurements were done to the nearest $0.01 \mathrm{~mm}$. The height of the nose was measured from the nasion to the subnasale using a sliding vernier calliper. To determine this height, measurements were taken at a point where the nasal bone intersects with the frontal bone (nasion) to the point where the nasal septum merges with the skin of the upper lip (subnasale). The width of the nose (maximum width of the nose) was measured at right angle to the nasal height from ala to ala.

Nasal Index was then calculated as follows:

Nasal Index $=($ Nasal width/Nasal height) multiplied by hundred. (Anas and Saleh, 2014)

Mathematically;

$$
\text { Nasal Index (N. I) }=\frac{\text { Nasal width }(\mathrm{NW})}{\text { Nasal height }(\mathrm{NH})} \times 100
$$

\subsection{Statistical Analysis}

Data were analyzed using SPSS Windows Version 14.0 (SPSS Inc, IBM, UK). Descriptive statistics of mean standard deviation and percentage were used to summarize the data obtained. Two-sided $\mathrm{P}$ values were calculated using the Paired sample T test for observed variables. P values $<0.05$ were considered statistically significant.

\section{Results}

The results consisting of the statistical analysis with respect to the nasal parameters (nasal height, nasal width and nasal index) of each ethnic group are shown in the tables below;

Table 1. The nasal height of the Igala, Ebira and Okun ethnic groups based on sex.

\begin{tabular}{llllllllll}
\hline \multirow{2}{*}{ Group } & Igala & \multicolumn{3}{c}{ Ebira } & \multicolumn{3}{c}{ Okun } \\
\cline { 2 - 9 } & Males & Females & P & Males & Females & P & Males & Females & P \\
\hline Mean \pm S.D & $46.19 \pm 4.02$ & $43.89 \pm 3.48$ & $*$ & $46.74 \pm 3.37$ & $43.80 \pm 3.70$ & $*$ & $46.01 \pm 3.52$ & $43.47 \pm 3.32 *$ \\
S.E & 0.54 & 0.48 & 0.45 & 0.66 & 0.47 & 0.46 & $\mathrm{~s}$ \\
N & 55 & 52 & 55 & 31 & 57 & 52 & \\
\hline
\end{tabular}

S.D- Standard Deviation; S.E- Standard Error; $n$ - number of subjects; * significant at $\mathrm{P}<0.001$.

* shows significant higher values in the nasal height of males compared to females.

Table 2. The Nasal Width of Igala, Ebira and Okun ethnic groups based on sex.

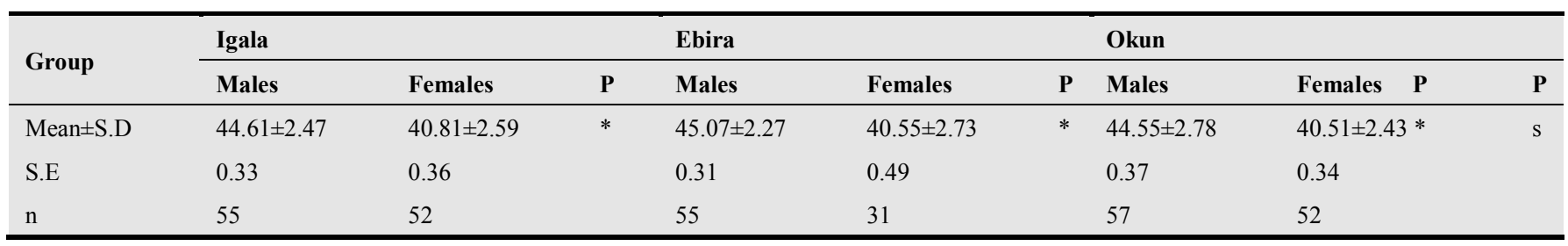

S.D- Standard Deviation; S.E- Standard Error; n- number of subjects; *- significant at $\mathrm{P}<0.001$.

* shows significant higher values in the nasal width of males compared to females.

Table 3. The Nasal Index of Igala, Ebira and Okun ethnic groups based on sex.

\begin{tabular}{|c|c|c|c|c|c|c|c|c|c|c|}
\hline \multirow{2}{*}{ Group } & \multicolumn{3}{|l|}{ Igala } & \multicolumn{3}{|l|}{ Ebira } & \multicolumn{4}{|l|}{ Okun } \\
\hline & Male & Female & $\mathbf{P}$ & Male & Female & $\mathbf{P}$ & Male & Female & $\mathbf{P}$ & $\mathbf{P}$ \\
\hline Mean \pm S.D & $97.21 \pm 8.88$ & $93.48 \pm 8.72$ & $*$ & $96.93 \pm 8.66$ & $92.99 \pm 7.62$ & $*$ & $97.23 \pm 7.89$ & $93.64 \pm 8.22$ & $*$ & $\mathrm{~s}$ \\
\hline S.E & 1.20 & 1.21 & & 1.17 & 1.37 & & 1.05 & 1.14 & & \\
\hline $\mathrm{N}$ & 55 & 52 & & 55 & 31 & & 57 & 52 & & \\
\hline
\end{tabular}

S.D- Standard Deviation; S.E- Standard Error; n- number of subjects; *- significant at $\mathrm{P}<0.05$.

* shows significant higher values in the nasal index of males compared to females. 
Table 4. Nasal parameters of Igala, Ebira and Okun ethnic groups based on ethnicity.

\begin{tabular}{|c|c|c|c|c|c|c|c|c|c|c|c|c|}
\hline \multirow{2}{*}{ Group } & \multicolumn{4}{|c|}{ Nasal Height } & \multicolumn{4}{|l|}{ Nasal Width } & \multicolumn{4}{|l|}{ Nasal Index } \\
\hline & Igala & Ebira & Okun & $\mathbf{P}$ & Igala & Ebira & Okun & $\mathbf{P}$ & Igala & Ebira & Okun & $\mathbf{P}$ \\
\hline Mean \pm S.D & $45.07 \pm 3.92$ & $45.68 \pm 3.75$ & $44.80 \pm 3.64$ & ns & $42.76 \pm 3.16$ & $43.44 \pm 3.27$ & $42.62 \pm 3.30$ & ns & $95.39 \pm 8.96$ & $95.51 \pm 8.47$ & $95.52 \pm 8.21$ & $\mathrm{~ns}$ \\
\hline S.E & 0.38 & 0.40 & 0.35 & & 0.31 & 0.35 & 0.32 & & 0.87 & 0.91 & 0.79 & \\
\hline $\mathrm{N}$ & 107 & 86 & 109 & & 107 & 86 & 109 & & 107 & 86 & 109 & \\
\hline
\end{tabular}

S.D- Standard Deviation; S.E- Standard Error; n- number of subjects; ns- not significant at $\mathrm{P}<0.05$.

' $n s$ ' shows no significant difference in the nasal parameters between the ethnic groups.

\section{Discussion}

The nose can be classified into three classes based on nasal index, as; Leptorrhine or fine nose (nasal index of 69.9 or less), Mesorrhine or medium nose (nasal index of 70.0-84.9) and platyrrhine or broad nose (nasal index of 85 and above).

In the present study (Table $1 \& 2$ ), the nasal index of the Igala, Ebira and Okun ethnic groups place them under the platyrrhine nose type. This is in conformity with previous researches conducted by Risley [19] that places the nose type of Africans into platyrrhine type. Oladipo [23] also reported a platyrrhine nose type in an analysis of the nasal indices of Igbo, Ijaw and Yoruba ethnic groups in southern Nigeria. In another study carried out among the Bekwaras in Cross River State, Nigeria; Esomonu [3] reported a platyrrhine nose type. However, a few studies have recorded mesorrhine nose type among some ethnic groups in Nigeria. Oladipo [24] reported a mesorrhine nose type for Andoni ethnic group of Rivers State in Nigeria, also Ikwerre males fell under the mesorrhine nose type [25], Ibibio females and Yakurr males of SouthSouth Nigeria [26] and Hausas of Northern Nigeria [4]. Staka [27] reported a leptorrhine nose type for the Kosovo Albanian population of which the mean nasal index was $65.46 \pm 6.32$ irrespective of sex. This shows that a racial variation exists in nasal index of various populations. The reason for the platyrrhinity of the Igala, Ebira and Okun ethnic groups of Kogi State can be linked to postulation made by Hall [9] that broader noses (Platyrrhine) are favoured in warm climates whereas narrower noses are favoured in cold climates. This distribution is identified as a consequence of natural selection [9]. The result of this study conforms to this postulation as the Igala, Ebira and Okun people are within the warmer climates of Nigeria.

From Table 1, 2 and 3, the Igala, Ebira and Okun males had significantly higher nasal height, nasal width and nasal index compared to their female counterparts $(\mathrm{P}<0.05)$ indicating sexual dimorphism. This result also conforms to previous studies where sexual dimorphism was observed. Oladipo [23] reported platyrrhine nose type in an analysis of the nasal indices of Igbo, Ijaw and Yoruba ethnic groups of southern Nigeria with males having significant higher nasal index than females $(\mathrm{P}<0.05)$. Eliakim-Ikechukwu [26] reported higher values of nasal parameters among the Yakurr females in the study of the nasal parameters of Ibibio and Yakurr ethnic groups in South- South Nigeria. Eboh [12] reported non-existence of sexual dimorphism in the study of the nasal indices among Benin adolescents in Edo State Nigeria. The reason for sexual dimorphism may be due to etiological factors as genetics and hormones [29].

From Table 4, there was no significant difference in the nasal parameters between the Igala, Ebira and Okun ethnic groups irrespective of their ethnicity. This is in conformity with the work of Eliakim-Ikechukwu [2] in the study of the nasal indices and bi-alar angle of the Ibo and Yoruba ethnic groups of Nigeria as there was no significant difference in the nasal indices between the Ibos and Yorubas. However, this study is in contrast to the work of Eliakim-Ikechukwu [26] in the study of the nasal parameters of Ibibio and Yakurr ethnic groups of South-South Nigeria as there was significant ethnic difference in the nasal parameters of the Ibibios and Yakurr. Also, Anas and Saleh [4] reported in the anthropometric comparison of the nasal indices between Hausa and Yoruba ethnic groups in Nigeria residing in Kano State that there was significant difference in the nasal indices between Hausas and Yorubas. Comparing the present study with that of Jovanovic [30] on the nasal morphological characteristics of the Serbian population (Caucaseans) with mean nasal index of 66.78 , it can be seen that the Igala, Ebira and Okun ethnic groups had higher values. This shows that variation exists in the nasal parameters of different ethnic groups and races. The reason for the similarities in the nasal parameters of Igala, Ebira and Okun ethnic group can be linked to postulations made by Farkas [31] that the nasal index is related to regional and climatic differences so, it is expected that ethnic groups in the same climatic region should have similarities in their nasal indices. The nasal indices of Igala, Ebira and Okun ethnic groups of Kogi State (North- central Nigeria) showed higher values when compared to the some studies on nasal indices carried out among some ethnic groups in Southern Nigeria though they all fell within the platyrrhine nose type. Oladipo [24] reported mean nasal indices of $86.38 \pm 1.35$ for the Okrika ethnic group of Rivers State, Nigeria in the anthropometric comparison of the nasal indices between Andoni and Okrika ethnic groups of Rivers State, Nigeria. Also, Eliakim-Ikechukwu [26] reported mean nasal indices of $86.58 \pm 1.20$ for the Ibibio males in the study of the nasal parameters of Ibibio and Yakurr ethnic groups of SouthSouth, Nigeria. This difference can be due to a warmer climate with mean higher temperature of $28.03^{\circ} \mathrm{C}$ in Kogi state [21] compared to $24.3^{\circ} \mathrm{C}$ in Rivers State [32].

\section{Conclusion}

In conclusion, Igala, Ebira and Okun ethnic groups fall under the platyrrhine nose type. In addition, the study showed the existence of sexual dimorphism in all the nasal 
parameters considered in each ethnic group with males having significantly higher values $(\mathrm{P}<0.05)$ than females. Also, this study supported the preposition that ethnic group living in the same climatic condition will have the same nose type as no significant difference was observed in all the nasal parameters between the Igala, Ebira and Okun ethnic groups. The results obtained from this study suggest that the nose could be a useful anthropometrical tool in separating gender and ethnic groups existing in different geographical location.

Further studies should be carried out among other ethnic groups in the northern parts of Nigeria and Africa for better comparisons with the values gotten from the major ethnic groups in Kogi State. The data obtained in this work is therefore recommended to forensic medics, anthropologists and clinicians (rhinoplastic surgeons).

\section{References}

[1] Oladipo, G., Udoaka, A., Afolabi, E. and Bob-Manuel, I. (2008). Nasal Parameters of Itsekiris And Urhobos Of Nigeria. The International Journal of Biological Anthropology. 3(1).

[2] Eliakim-Ikechukwu, C., Bassey, T. and Ihentuge, C. (2012). Study of the Nasal Indices and Bialar Angle of the Ibo and Yoruba Ethnic groups of Nigeria. Journal of Biology, Agriculture and Healthcare, 2(11):149-152.

[3] Esomonu, U.G., Ude, R.A., Lukpata, P.U. and Nandi, E.M. (2013). Anthropometric study of the nasal index of Bekwara ethnic group of cross river state, Nigeria. International Research Journal of Applied and Basic Sciences, 5(10):12621265.

[4] Anas, I.Y. and Saleh, M.S. (2014). Anthropometric Comparison of Nasal Indices between Hausa and Yoruba Ethnic Groups in Nigeria. Journal of Scientific Research and Reports, 3(3):437-444.

[5] Sarka ,J. (2014). Important Criteria for Racial Identification. Biology. The next Generation Library.

[6] Porter, J.P. and Olson, K.L. (2003). Analysis of the African American female nose. Plastic Reconstruction Surgery, 111(2): 627-628.

[7] Alex, F.R., Steven, B. and Timothy, G.L. (1996). Human Body Composition. $4^{\text {th }}$ ed. Human Kinetics Publishers, pp.167-172.

[8] Olotu, J.E., Eroje ,A., Oladipo, G.S. and Ezon-Ebidor, E. (2009). Anthropometric study of the facial and nasal length of adult Igbo ethnic group in Nigeria. The International Journal of Biological Anthropology, 2(2).

[9] Hall, R.L. and Hall, D.A. (1995). Geographic variation of native people along the Pacific Coast. Human Biology, 67(3): 407-426.

[10] Sinnatamby, C.S. (2006). Last's Anatomy: Regional and Applied. $11^{\text {th }}$ Ed. Edinburgh: Churchill Livingstone, pp. 385.

[11] Heidari, Z., Mahmoudzadeh-Sagheb, H., Khammar, T. and Khammar M. (2009). Anthropometric measurements of external nose in 18-25-year-old Sistani and Baluch aborigine women in the southeast of Iran. Folia Morphology .68(2):8892.
[12] Eboh, D. E. O. (2011). Nasal indices among Bini adolescents in Edo State, Nigeria. International Journal of Morphology, 29(4):1231-1234.

[13] Kashmira, L.(2011). Different Type of Noses. Available in: http://www.buzzle.com/articles/different-types-of-noses.html.

[14] Willams, P., Dyson, M., Dussak, J.E., Bannister, L.H., Berry, M.M., Collins, P. and Ferguson, M.W.J. (1995). Skeletal System. Gray's Anatomy. 3rd Ed. Edinburgh: Churchill Livingstone, pp.609-612.

[15] Jimoh, R.O., Alabi, S.B., Kayode, A.S., Salihu, A.M. and Ogidi, O.D. (2011). Rhinometry: spectrum of nasal profile among Nigerian Africans. Brazilian Journal of Otorhinolaryngology, 77(5):589-593.

[16] Sparks, C.Z. and Jantz, R.L. (2002). A reassessment of human cranial plasticity: boas revisited. Proceeding of the National Academy of Sciences, 99:14636-14639.

[17] Xu, B., Wang, Y., Ma, J., Li, M. and Xu, L. (2011). A computer-aid study on the craniofacial features of Archang race in Yunnan province of China. Hua Xi Kou Qiang Yi Xue Za Zhi. 19(6):394-396.

[18] Ofodile, F.A. and Bokhari, F., (1995). The African American nose: part II. Annals of Plastic Surgery, 34(2):123-129.

[19] Risely, H.H.(1915).The People of India. 2nd ed. Delhi: Oriental books. ReprintCorporation, 1969, pp. 395-399.

[20] Carleton, D.C. (1989). The race of Europe, the European Anthropometry. $5^{\text {th }}$ ed. London:Macmillian publishers, pp. 993.

[21] Audu, E.B. (2012). An Analytical View of Temperature in Lokoja, Kogi State, Nigeria. International Journal of Science and Technology,2(12):856-859.

[22] Encyclopædia Britannica (2014). Ultimate Reference Suite. Chicago: Encyclopædia Britannica. Volume 2 No 14.

[23] Oladipo, G.S., Olabiyi, A.O., Oremosu, A.A. and Noronha, C.C. (2007). Nasal indices among major ethnic group in southern Nigeria. Scientific Research and Essay, 2(1): 20-22.

[24] Oladipo, G.S., Eroje, M.A. and Fawehinmi, H.B. (2009). Anthropometric comparison of the nasal indices between the Adoni and Okrika ethnic groups of Rivers State, Nigeria. International Journal of Medical Science, 1(4):135-137.

[25] Oladipo, G. S., Oyakhire, M. O. and Ugboma, H. A. A. (2010) Anthropometric Studies of Nasal Indices of the Ekpeye and Ikwerre Ethnic Groups in Nigeria. Asian Journal of Medical Science, 2(4):167-169.

[26] Eliakim-Ikechukwu, C., Iro, C.M., Ihentuge, C.J. and Bassey, T.E. (2013). Nasal Parameters of Ibibio and Yakurr Ethnic Groups of South- South Nigeria. Journal of pharmacy and Biological Sciences, 5(6):23-26.

[27] Staka, G.,Dragidella, F. and Disha, M. (2012). Anthropometric studies of nasal index of the Kosovo Albanian population. Antrocom Online Journal of Anthropology, 8(2): 457-462.

[28] Oladipo, G. S., Okoh, P. D., Akande, P. A. and Oyakhire, M. O. (2011). Anthropometric study of some craniofacial parameters: head circumference, nasal height, nasal width and nasal index of adult Omoku indigenes of Nigeria. American Journal of Scientific and Industrial Research, 2(1):54-57. 
[29] Sharma, S.K., Massarat, J., Raj, L.S., Sudhir, S., Akhilesh, T. and Vipendra, B. (2014) Anthropometric Comparison of Nasal Parameters between Male and Female of Gwalior Region. Journal of Dental and Medical Sciences, 1(5):57-62.

[30] Jovanović, J., Jeremić, D., Jovanović, B., Maja V., Sazdanović, P., Maja, S., Neda, O., Stojadinović, D., Katarina, J., Marković, N, and Ivana, Z. (2014). Nasal morphological characteristics of the Serbian population. Archives of Biological Science Belgrade, 66(1): 227-234.
[31] Farkas, L.G., Kolar, I.R. and Munro, I.R. (1986). Abstract on the geography of the nose, a morphometric study. Aesthetics and Plastic Surgery, 10(4) :191-223.

[32] Sanusi, Y.K., Abisoye, S.G. and Faluyi, O.O. (2013). Estimation of Temperature - Humidity Index in Some Selected Locations in Nigeria. Research Journal in Engineering and Applied Sciences 2(1):70-73. 